\title{
SPINAL DEFORMITIES IN TRAUMATIC PARAPLEGICS AND TETRAPLEGICS FOLLOWING SURGICAL PROCEDURES
}

\author{
By Sir Ludwig Guttmann, C.B.E., M.D., F.R.C.P., F.R.C.S. \\ Stoke Mandeville Hospital, Aylesbury, England
}

DEFORMITIES of the vertebral column, whether caused by congenital abnormalities or as a result of illness such as tuberculosis and polio, or injuries to the spine, have been the subject of medical treatment for thousands of years. Conservative methods of reduction and alignment of vertebral fractures, with or without spinal

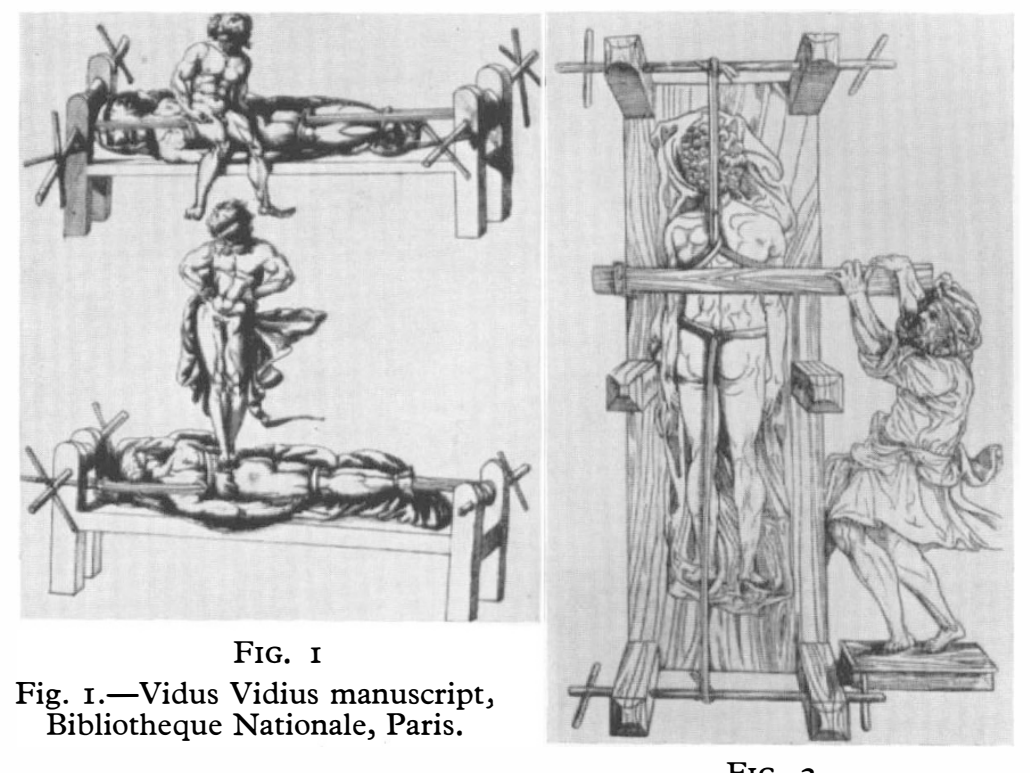

FIG. 2

Fig. 2.-De Machinamentis (Oribasius). In: Vidus Vidius: Chirurgia, e Graeco in Latinum connersa, Paris 1544 .

cord involvement, did not differ from that employed for the tuberculous gibbus. They were based in principle on Hippocrates' famous extension bench-better known, through the work of Celsius, as scamnum-and re-alignment of the spine was achieved in ancient and mediaeval times by forceful and brisk procedures, as described and so well-illustrated by Vidus Vidius in the sixteenth century. The victim, lying on a bench in prone position, was pulled extended from the shoulder upwards and distally from the hips, while the medical attendant either stood or sat on the gibbus or a cross-bar was pressed on to the gibbus until it disappeared (figs. I and 2).

This violent procedure was still used, with some modification, in the nineteenth century by Jean Francis Calot, manipulating the spinal deformity with his fists. I witnessed this method in 1917 when, before taking up medicine, I worked as an 
orderly in the Accident Hospital for Coalminers (Knappschaftslazarett) in my home town in Upper Silesia. It was executed by the surgeon in charge, Dr. Hartmann, in a case of fracture dislocation of the thoraco-lumbar junction with paraplegia. The only difference to Calot's technique was that the patient was held in the air in supine position by two assistants extending the patient under the armpits and two extending the pelvis and legs, while the surgeon reduced the dislocation by forceful manipulation with his fists from below.

In the 20's and 30's of this century, methods of postural reduction by hyperextension were introduced, such as on slings, frames or hammock in prone position, as described by Davis (1929) and Rogers (1930), or hanging (Böhler, 1930), and

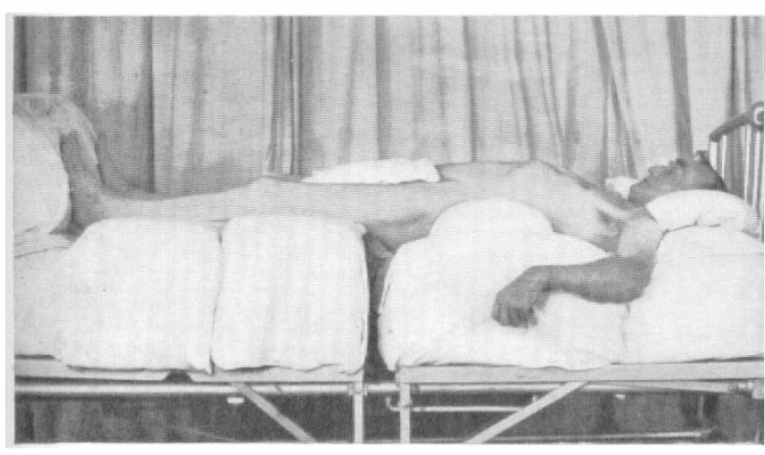

A

FIG. 3

A, Postural reduction of a fracture dislocation of the thoral lumbar junction on sorbo rubber packs. $\mathrm{B}$, Patient in lateral position maintained by a sand bag in position.

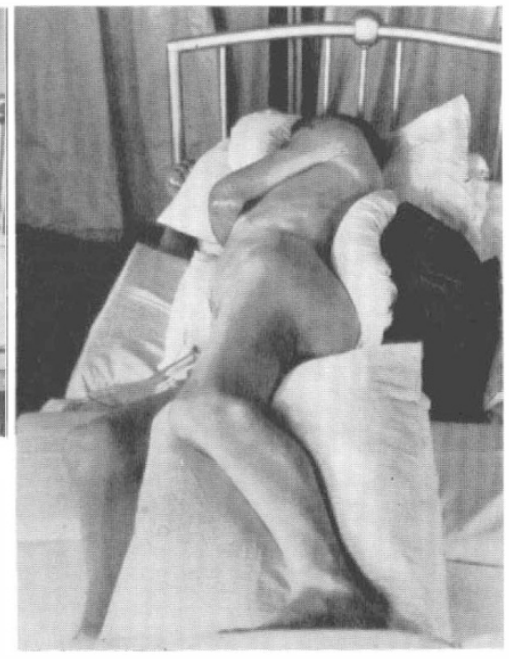

B

by Watson-Jones's two-table method (I93I, I934). This was followed by application of plaster jackets extending from the symphysis pubis below to the clavicles above. However, other schools (Magnus) renounced these methods of reduction and, accepting the spinal deformity, advocated consolidation of the fractured spine by placing the patient flat in his bed in supine position.

Obviously, all these methods proved to be unsatisfactory in fractures and fracture-dislocations of the vertebral column resulting in paraplegia, as pressure sores with all their disastrous consequences could not be prevented. Moreover, to accept the defeatist attitude of renouncing reduction of the broken spine and allowing the patient to lie flat without attempting to restore, as far as possible, the physiological position and the normal curvature of the vertebral column, seemed to many surgeons to be unacceptable.

During the Second World War I introduced at Stoke Mandeville a method of postural reduction in hyperextension by placing the patient in supine position, first on pillow packs, later improved by sorbo-rubber packs, with additional pillow support underneath the fracture and regular two-hourly turning, day and night, from the supine onto the lateral position by three or four members of the staff (figs. 3, $a$ and $b$ ). By this method of gentle, postural reduction, aimed at restoring and maintaining the normal curvature of the spine, stable as well as unstable 
fractures, including fracture-dislocations of the worst type, could be reduced in the vast majority of cases most satisfactorily, the angulation of the vertebral column repaired, and at the same time pressure sores were altogether avoided (fig. 4). See also Guttmann (1954, I967). Once the spine was consolidated, as shown by control $\mathrm{X}$-rays, the patient was allowed to get up, wearing for several weeks a light plastic support.

The disavantage of this procedure, was the continuous strain on the nursing staff. Therefore, in 1965 , following previous experiments with various turning beds to obviate the arduous task of the nursing staff and to diminish the number of orderlies, I introduced, with the co-operation of Egerton Engineering Ltd., Horsham, Surrey, an electrically-controlled turning and tilting bed, which has

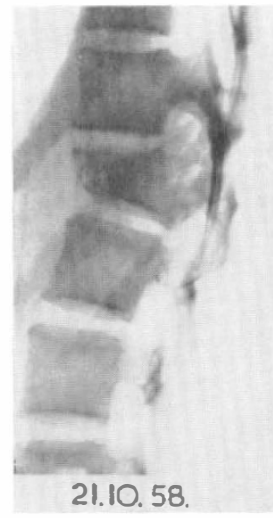

21.10. 58

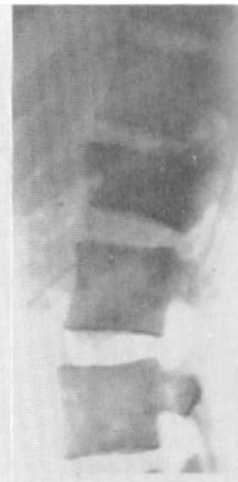

22.12.58.

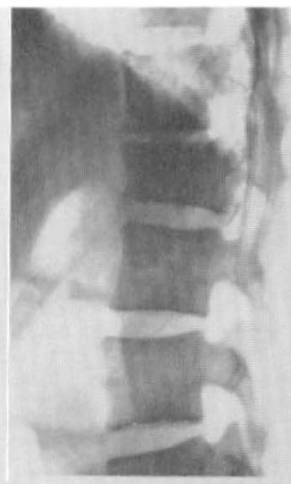

26.6.59.

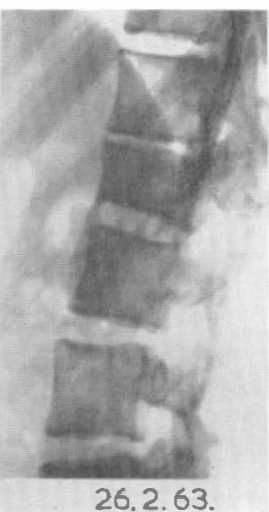

26.2.63.

FIG. 4

Unstable fracture dislocation of the first lumbar vertebra with chipping off the upper anterior third of the body, dislocation of the posterior part of the body and fracture of the pedicel. Very satisfactory reduction, consolidation and fixation of the broken vertebra which in due course re-expanded.

proved very satisfactory in reducing the broken spine and preventing sores not only in traumatic paraplegics but, by adding a special head traction unit, also in tetraplegics (fig. 5) (Guttmann, 1965, 1967).

However, whatever conservative method of realignment and consolidation of the fractured spine is used, it must be readily admitted, although so far statistically not determined, that in due course an initially well-erected broken vertebra may collapse later, resulting in angulation and deformity ${ }^{1}$ of the spine to a greater or lesser degree, as a result of avascular necrosis or, in a small number of cases, from redislocation. In this connection, the degree of the initial dislocation and vertebral destruction does not seem to be the decisive factor of a collapse of the vertebral body and susequent spinal deformity. Kümmel (I89I-I928) has drawn attention to the rarefaction and collapse of a vertebral body weeks or months after a trivial trauma to the spine with subsequent kyphosis formation in patients who, immediately after injury, showed no radiological abnormality. Amongst the cases of what the French called 'Syndrome de Kümmel-Veneuil', quoted in the literature, circulatory disturbances have been accepted by various authors as playing at least an essential part in this pathology (Schmorl, I927; Lob, I954). 
For many years, in particular since the introduction of asepsis and radiology, it has been the endeavour of many surgeons to replace conservative methods by open reduction with or without laminectomy followed by internal fixation of the broken spine in traumatic paraplegics and tetraplegics, to combat spinal deformity, prevent redislocation and decompress the spinal cord. This dynamic approach naturally aroused controversies between the advocates of conservative and operative procedures, which have never ceased since the heated dispute between Sir Charles Bell and Sir Stanley Cooper in the early years of the nineteenth century. Moreover, even amongst the advocates of surgical procedures, there is discrepancy

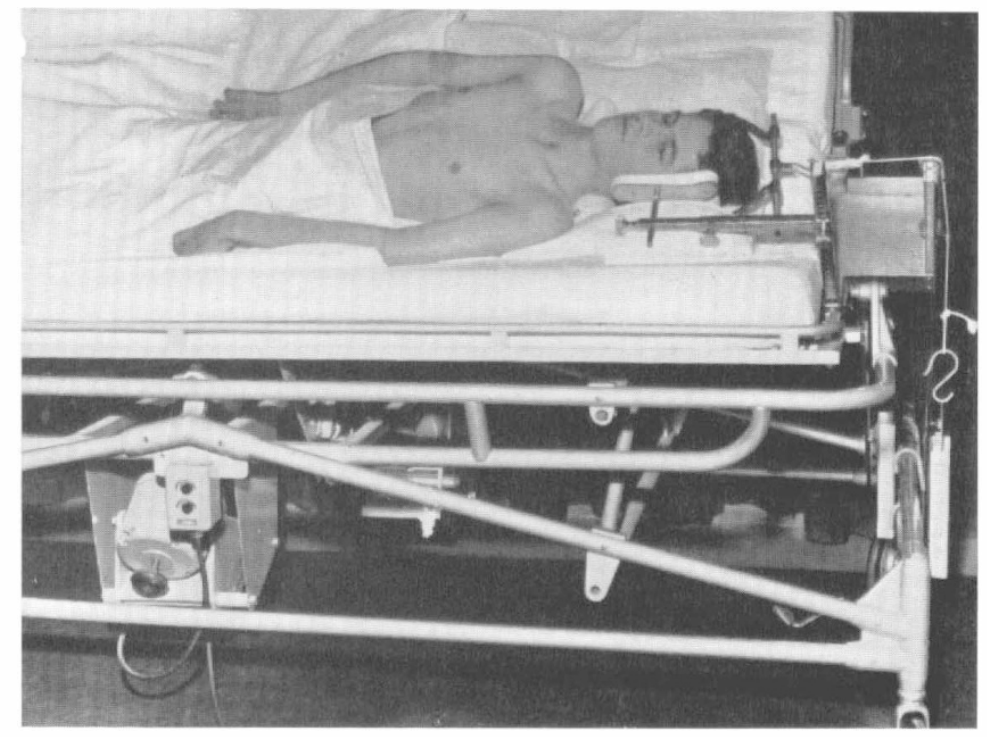

FIG. 5

The Stoke Mandeville-Egerton electrical turning and tilting bed; the picture shows a traumatic tetraplegic in lateral position on skull traction.

of opinion as to the best method of re-aligning the broken vertebra to prevent spinal deformity later and, in particular, also to the timing of surgical intervention after injury. Many surgeons still advocate immediate or very early surgical intervention following fractures or fracture-dislocations with involvement of the spinal cord, regardless of whether the cord lesion is complete or incomplete. In the following, the various methods will be discussed in the light of this concept.

Laminectomy. The ill-conceived idea that compression of the spinal cord following vertebral fracture is the main, if not the only, cause of paraplegia and tetraplegia and that immediate laminectomy is necessary to decompress the cord still leads many surgeons, especially neurosurgeons, to the indiscriminate use of this procedure. However, it must be remembered that the mechanism of spinal cord injury following fractures and dislocations differs fundamentally from that of a slow-growing spinal tumour or tuberculous process of the spine. The injury producing instantaneous clinical symptoms of a complete or partial paralysis is 
the result of the acute impact of the violence on the neural elements themselves and their vascular supply, causing, commensurate with the degree and direction of the impinging force, concussion, contusion, laceration, and semi- or complete transection of the cord. It must be stressed that the deformity of the spine-i.e. narrowing of the vertebral canal by penetrating bone or intervertebral disc lesion, as demonstrated by X-ray, is not in itself evidence of cord compression as the cause of paraplegia and tetraplegia. It is a well-established fact that, in spite of X-ray evidence of marked vertebral abnormality in extension, flexion, rotation, and even lateral direction, the neurological deficit may be either minimal or even entirely absent. Striking examples of this fact have been published (Guttmann, I954, I96I; Meinecke, 1964). Moreover, it is my experience that considerable and almost complete recovery of an initially more or less severe neurological deficit may occur, in spite of persistent vertebral deformity resulting from a non- or only partially reduced vertebral dislocation with or without sub-arachnoidal block. Having regard to the tremendous numbers of laminectomies, both exploratory and decompressive, which have hitherto been carried out, there should now be abundant and overwhelming statistical proof of the therapeutic superiority of this management in the initial and early stages of paraplegia and tetraplegia, as compared with the conservative management. Comparative statistics on a large scale (Comarr, I959; Geisler, Wynne-Jones and Jousse, I966) have failed to prove any advantage of immediate and early laminectomy in traumatic lesions of the spinal cord. Moreover, the detrimental effect of indiscriminate immediate and early laminectomy increasing the cord damage in incomplete cord lesions is by no means a rare incident, and there has been enough evidence of this if one considers only those cases, especially cervical injuries, reported in the literature (Taylor, I929; Merle d'Aubigné, Benassy and Ramadie, 1956; Harris, 1963; Holdsworth, 1963; and others). It may be noted that authors who had been very enthusiastic in advocating immediate laminectomy for one reason or another, in particular in incomplete lesions, have changed their views in the light of greater experience. Covalt, Cooper, Hoen, and Rusk (1953) propagated laminectomy with the argument that this procedure carried 'a low mortality and morbidity rate'. This can hardly be accepted from either a medical or an ethical point of view. Nor is their other argument acceptable by anyone who is familiar with the pathology of the spinal cord following injury 'that unless it has been determined by surgical exploration that the spinal cord has been transected one cannot conclude during the early weeks after injury that a patient is permanently or irreversibly paraplegic'. Certainly, no conclusion can be drawn from the macroscopic appearance of the cord as to the prognosis of functional recovery, if at operation the continuity of the spinal cord is found to be intact, as the irreversible damage to the cord can be vascular, due either to anterior spinal artery thrombosis or haematomyelia. However, further experience of this 'dynamic' surgical approach must have fundamentally changed the views of workers in that department, for a recent publication from the same institute (Kaplan, Powell, Grynbaum and Rusk, 1966) frankly admits that development of paralysis following laminectomy is not a rare occurrence and that 'this complication points out the need to be extremely circumspect in exploratory laminectomy when the degree of paralysis is minimal'. This warning should, of course, apply equally to incomplete lesions with a greater degree of neurological deficit. It cannot be stressed too strongly that, in the immediate stage of spinal cord lesion, it is not primarily the vertebral deformity resulting from injury which determines the 
indication for exploratory laminectomy but the neurological symptomatology, especially in cervical lesions. Indiscriminate hasty operative procedures are known to have had disastrous results not only in increasing the neurological deficit, including transforming incomplete lesions into complete ones, but, especially in cervical cord injuries, resulting in early death of the patient, due to increased respiratory complications.

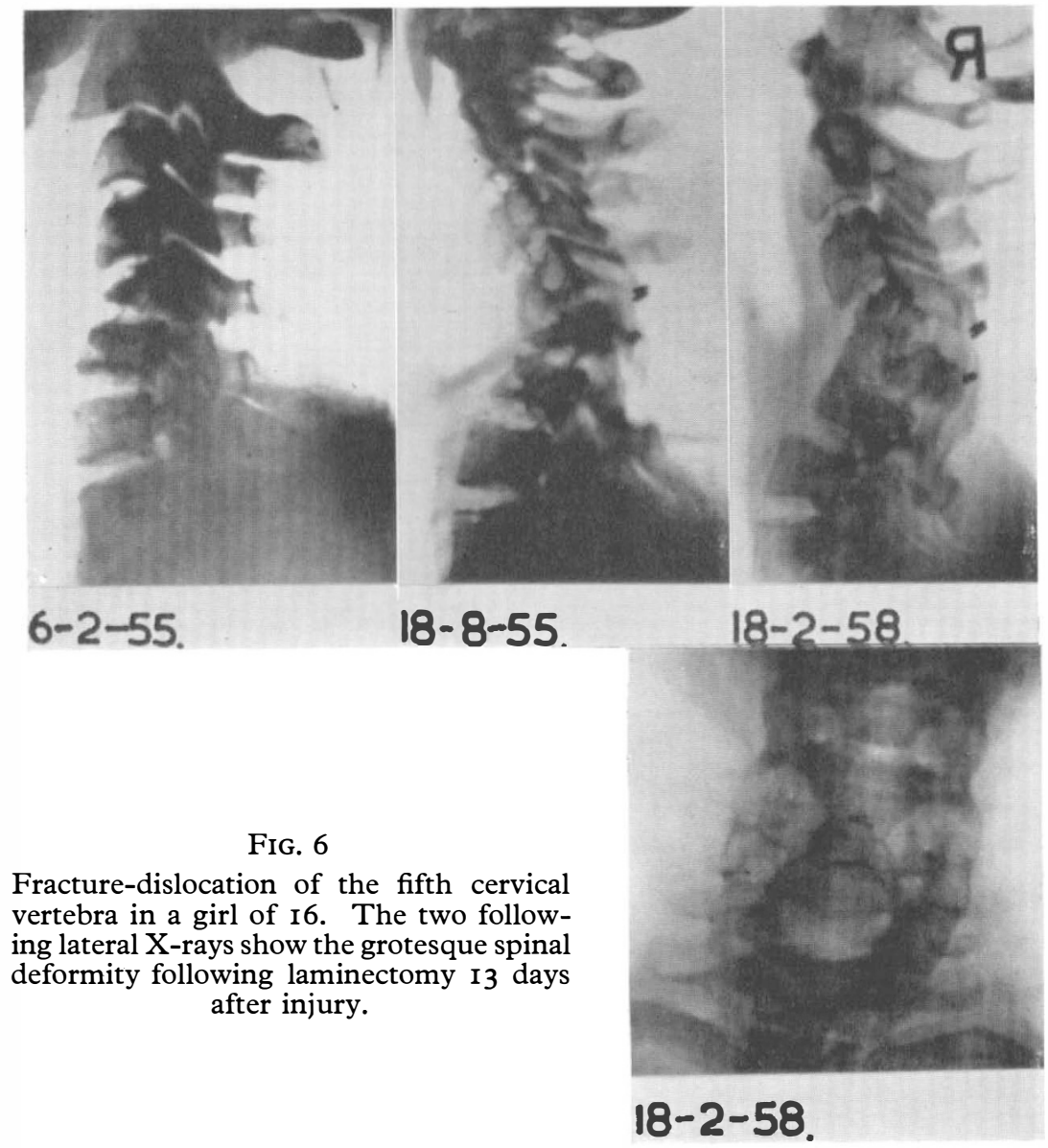

With regard to the rare circumstances in which early, although not immediate exploratory laminectomy may be justified, I refer to previous publications (Guttmann, 1949, 1967).

It is now well known that the initial vertebral deformity may greatly increase following laminectomy. What grotesque dimensions this can assume is shown by the X-rays of a I6-year-old girl who sustained an incomplete tetraplegia below C5/6 as a result of a fracture-dislocation of the 5 th cervical vertebra of moderate degree. She had a laminectomy 13 days after injury by a highly skilled neurosurgeon. X-rays subsequent to this operation show a profound increase of the vertebral deformity (fig. 6) although at operation 'there appeared to be no 
instability of the spine' and following discussion with orthopaedic observers 'it was unanimously decided that there was no need for grafting or other stabilising manipulations'. In spite of the grotesque bony deformity, the incomplete transverse spinal syndrome in this case did not become complete, and the patient, although severely handicapped in her hands, was able to walk slowly on elbow crutches-indeed, an amazing degree of adaptability of the spinal cord to such profound deformity of the whole cervical spine. This confirms the well-known fact that, at the time of the initial injury, the spinal cord may be only slightly damaged or may even escape damage completely, in spite of a profound fracture dislocation. By carring out a laminectomy in such a case, the danger of increasing the initial traumatic spinal deformity, let alone increasing or producing neurological deficit is, in my view, great, particularly in children and young adults.

Open Reduction and Internal Fixation by Plating, Wiring and Fusion. During the war, Albee (I940) recommended open reduction of fracture dislocation
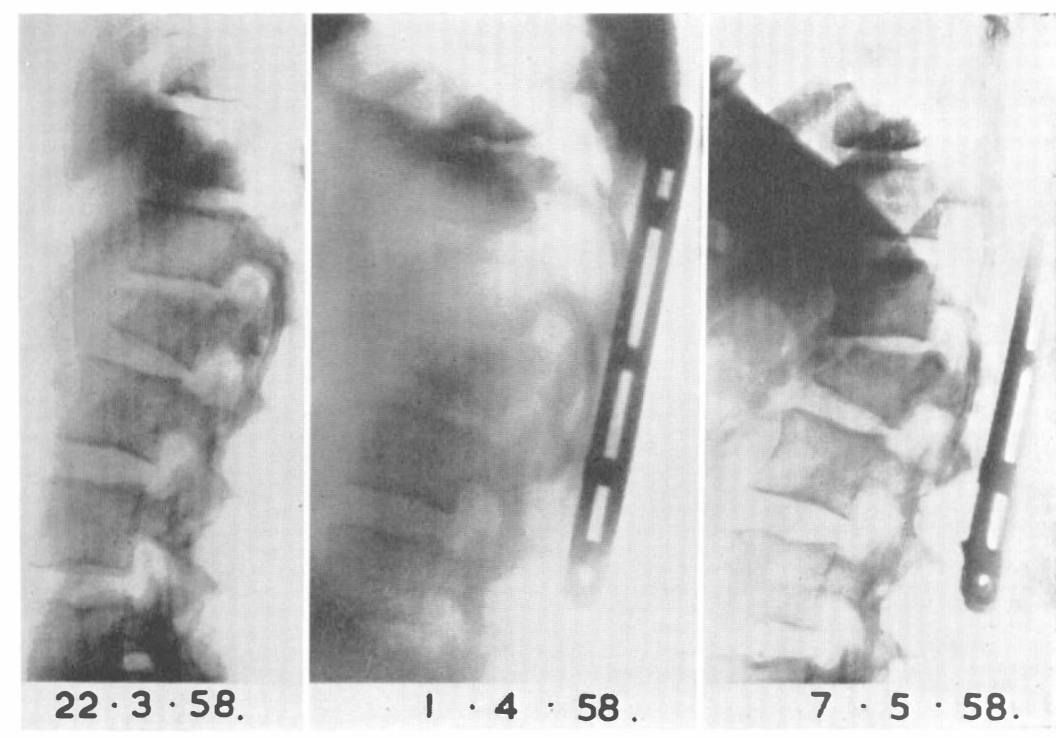

FIG. 7

Fracture dislocation of the first lumbar vertebra treated by Meurig-Williams plates. The third X-ray shows re-dislocation of thebroken vertebra initially reduced and angulation of the vertebral column.

of the spine and fixation by bone grafts, and Wilson in the U.S.A. introduced fixation of the broken spine by metal plates. But this method did not receive general acclaim by orthopaedic and neurological surgeons, until Holdsworth and Hardy (I953), who condemned manipulative reduction as being usually unsafe, revived open reduction and internal fixation by bolting two metal plates through one or more spinous processes above and below the level of the dislocation. This method was advocated for fracture-dislocations of the spine at the thoraco-lumbar 
level only. The authors described this method as simple, safe and effective, moreover that it would promote recovery of the cord or roots and prevent further damage.

Pennybacker (1953) suggested that this method would prevent later angulation, and Dick (1953) stated that the spine could be stabilised in this way so securely that 'ordinary' nursing handling is absolutely safe and 'there is no danger of further damage to recovering nerve roots'. Hardy (1965) apparently did not agree with the latter view, as the nursing of his operated cases was carried out with the same routine and care as in the non-operated cases, much on the same lines as practised at Stoke Mandeville since 1944, with the exception that the patient was rolled from the supine to the lateral position, instead of being lifted and turned by three or four members of the staff. Holdsworth (1954) publicly withdrew his statement that this method was simple. Yet, in spite of this warning, it was taken up by a great number of orthopaedic surgeons, who used this method not only in fracture dislocations of the throacic spine but in simplewedge fractures and, furthermore, at any level of the spine, including even the cervical spine. We have admitted to Stoke Mandeville over Ioo patients in whom open reduction with metal plates have been carried out elsewhere, and the conclusions which can be drawn from this large material are as follows:

(I) This method does not prevent redislocation, regardless of what kind of metal plate is used. This applies in particular also to that large, straight plate propagated by Meurig Williams, as shown in Figure 7. In fact, in some patients this type of plate produced such stiffness and rigidity of the vertebral column, associated with excrutiating pain, that the patient was not able to bend and the plate had to be removed, as was also necessary after a number of Wilson plates. Figure 8, A, shows the fracture dislocation immediately after injury and the reduction after plating with a Meurig-Williams plate. Figure 8, B, shows the patient trying to bend before the plate was removed and after.

(2) This method does not prevent later collapse of the initially expanded fractured vertebra, as shown in Figure 9. Consequently, in such cases it does not prevent later angulation of the vertebral column of even the most profound degree, sometimes resulting in a gibbus of the worst type (figs, IO, A and B).

(3) Plates have been fixed on the wrong vertebrae and have either had to be removed by a second operation or another plate has had to be inserted.

(4) Once a patient is out of bed and mobile, it is not unusual for the plates to become loose so that they cut out of the spinous processes and have to be removed. This is in accordance with Holdsworth's own views (Holdsworth, I963), but in our experience it is not a question that the plates have served their purpose, as claimed by Holdsworth, but that they are detrimental to the patient, causing pain and rigidity of the spine.

(5) Haematomata and infection following this operation have occurred.

(6) Lastly, but by no means least, there is no proof whatsoever that this operation promotes more root escape and better neurological recovery than conservative methods. This has been pointed out statistically by Hardy himself in 1965 .

(7) There have been instances where the clinical symptoms deteriorated following this operation. 

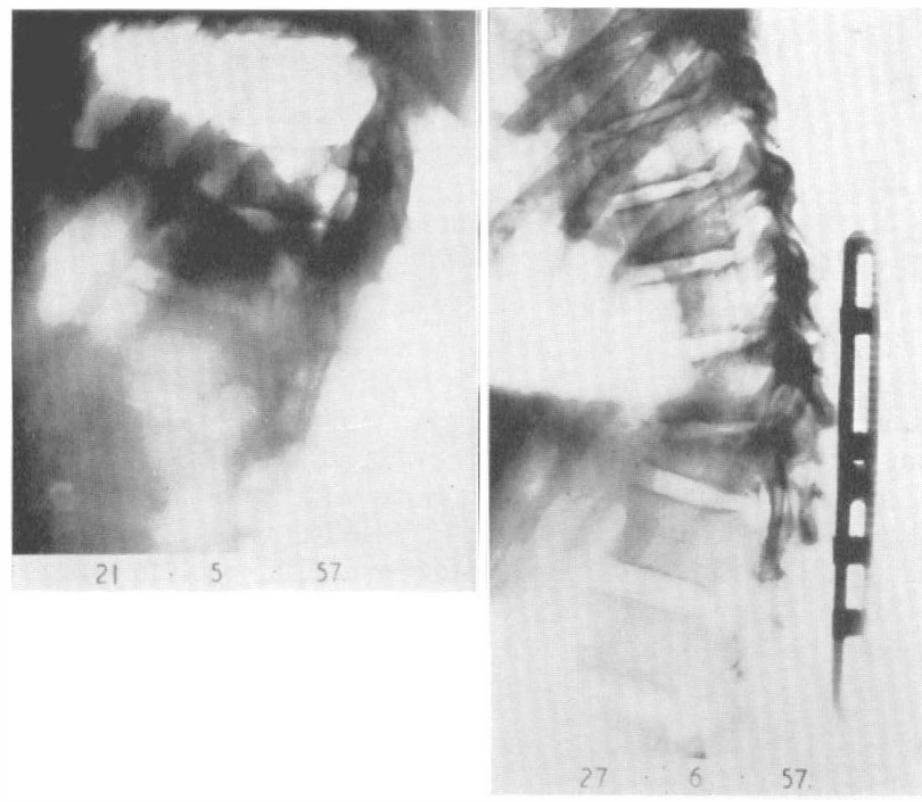

A

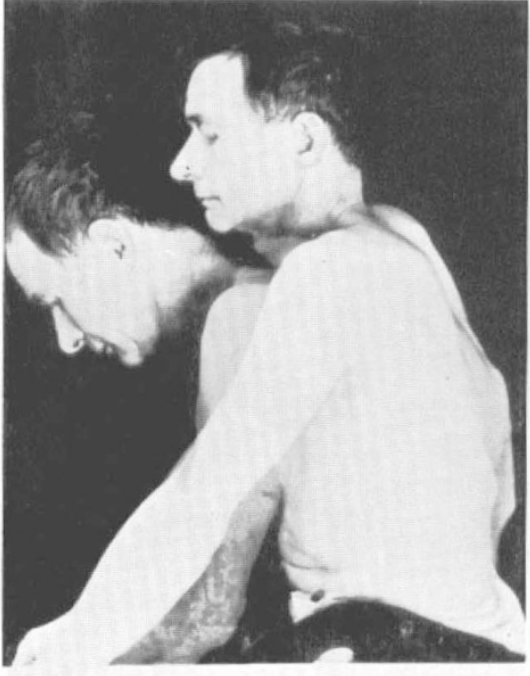

BEFORE REMOVAL OF PLATE.

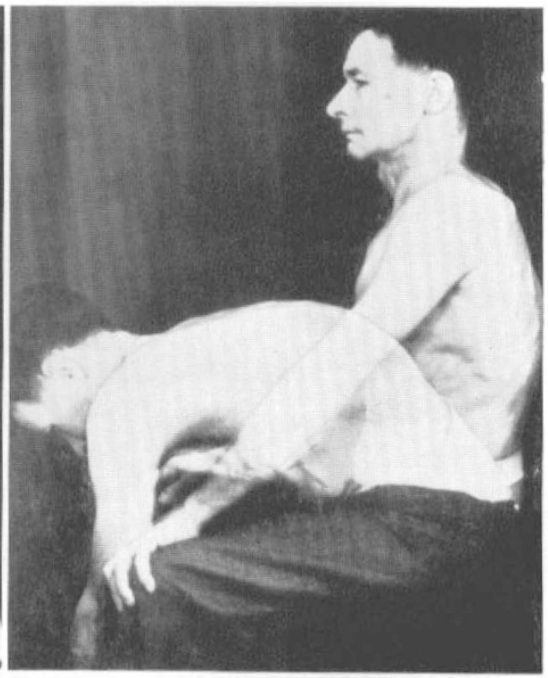

AFTER REMOVAL OF PLATE.

B

FIG. 8

A, Fracture dislocation of the I2th thoracic vertebra open reduction and plating by Meurig-Williams plates. Plating does not prevent later collapse of the broken vertebra and angulation of the spine. $\mathrm{B}$, Profound stiffness of the patient before removal of plate and condition after removal. 
It may be noted that, in recent years, Holdsworth and Hardy have become very selective, by using this method only in unstable fractures with the worst displacement, whilst their conservative series includes those with 'relatively less evidence of instability' (Hardy, 1965). These views would now coincide with those I expressed in 1954, 'that open reduction in traumatic paraplegics, followed

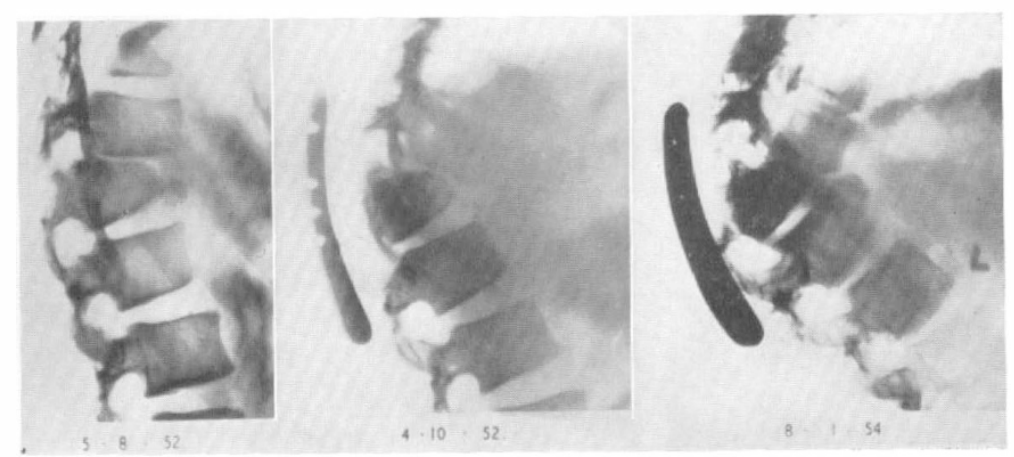

FIG. 9

Fig. 9.-Fracture dislocation of the first lumbar vertebra, open reduction and plating by Wilson plate resulting in grotesque angulation of the spine.

Fig. Io.-Demonstrating the profound gibbus of the patient.

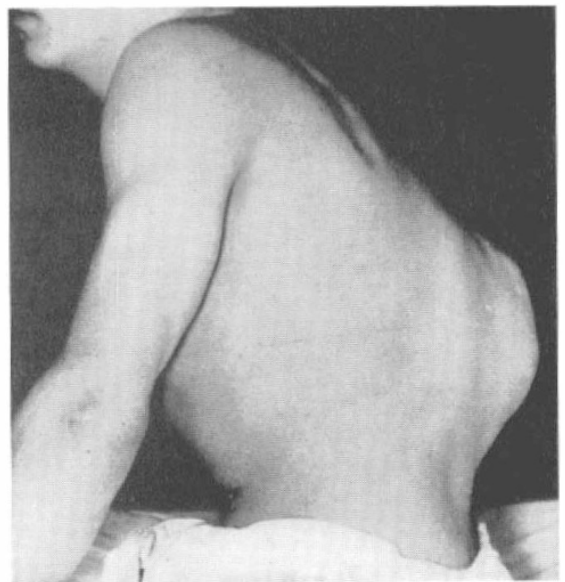

FIG. IO

by internal fixation by plating or bone grafts, has its indication, if at all, only in the most excessive type of fracture-dislocation'. However, Holdsworth (I963) still maintains that unstable fractures cannot be stabilised in the early stages by conservative methods. This is not my experience in the great number of cases I have treated by the method of postural reduction described above. This applies to extension, flexion, compression, and burst fractures, or dislocations, the latter being considered as unstable, due to the complete rupture of the posterior ligament complex. I consider that these dislocations can be safely reduced and stabilised conservatively in the majority of cases. There is still time to consider fixation by operation at a later stage, if major redislocation occurs and, in particular, the neurological symptoms increase. 
In recent years, anterior and posterior fusion by bone grafts and fixation of the spine by wire have been advocated in incomplete and complete lesions. So

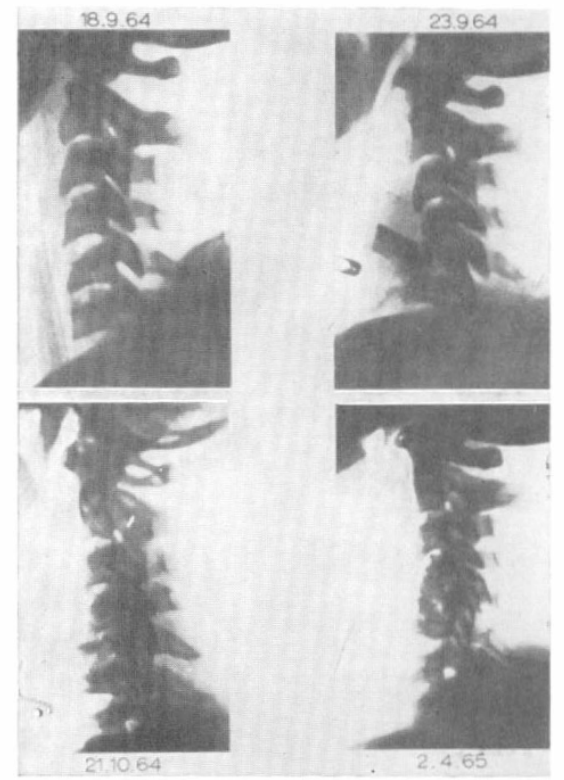

FIG. I I

Compression-split fracture of 5 th cervical vertebra. Immediate anterior fusion and grafting. The condition of the graft 5 dayslater (23 September I964) and the subsequent pathological changes the cervical spine.

far there have been very few publications which show that these operative procedures have their hazards (Verbiest, I963), which doubtless occur. Figure I I shows what can happen in an anterior fusion in a case of complete traumatic tetraplegia carried out elsewhere by a skilled neurosurgeon. As can be seen, the primary fracture-dislocation was a mild one and would have consolidated quite easily. However, following anterior fusion by bone graft, not only did the graft disengage itself, requiring immediate removal, but, as shown in the subsequent X-rays, the result was a marked deformity of the cervical spine, involving even three vertebrae. The tragic results of a hasty posterior fusion with bone graft in a very incomplete cervical lesion have been published elsewhere, (Guttmann, 1967)

In conclusion, from all these experiences, I have no reason whatsoever to change my views, expressed for so many years, that deformity of the broken spine can, in the majority of patients, be successfully reduced and consolidated by conservative postural reduction, and deformity of the spine either prevented or reduced. Operative procedures in the acute and early stages following traumatic paraplegia and, in particular, tetraplegia, have their indication, if at all, only in very selected cases (Guttmann, I967).

\section{REFERENCES}

Alby, F. (1940). Bone Graft Surgery. New York: Appleton.

BöHLER, L. (1935). The Treatment of Fractures. Bristol: Wright \& Son.

Comarr, E. (I959). F. Int. Coll. Surgeons, 3I, 437.

Covalt, D. A., Cooper, I. S., Hoen, T. \& Rusk, H. (1953). Am. med. F. 151, 89.

Davis, A. G. (1929). F. Bone Foint Surg. II, I33.

Dick, I. L. (I953). Edinburgh med. F. 60, 249.

Geisler, W. O., Wynne-Jones, M. \& Jousse, A. T. (i966). Med. Service J., Canada 22, 512 .

Guttmann, L. (1946). Nursing Times, 42, 798.

Guttmann, L. (I949). F. Bone foint Surg. 3IB, 389.

Guttmann, L. (I954). Proceed. Roy. Soc. Med. 47, Vol. I2.

Guttmann, L. (1956). The Practitioner, 176, I 57.

GutrmanN, L. (I967). Jubilee Book for Sir Harry Platts' 8oth Birthday, I8-28. Publ National Fund for Research into Crippling Diseases, London.

Guttmann, L. (1967). Brit. med. F. 1, 288.

Hardy, A. G. (1965). Paraplegia, 3, II2. 
HARRIS, P. (1963). Symposium on Spinal Injuries, p. 105. R. Coll. Surg. Edinburgh.

Holdsworth, F. W. \& Hardy, A. G. (I953). F. Bone foint Surg. 35B, 540.

Holdsworth, F. W. (1963). Symposium on Spinal Injuries, p. I6I. R. Coll. Surg., Edinburgh.

Kaplan, L., Powell, B. R., Grynbaum, B. B. \& Rusk, H. (1966). Comprehensive follow-up Study of Spinal Cord Dysfunctions, pp. 13-17. New York.

KüMmel, H. (1928). Arch. Orthop. Chir. 26, 47I.

LoB, A. (1954). Die Wirbelsäulen-Verletzungèn und ihre Ausheilung, p. 87. Stuttgart: Thieme.

MeineCKe, F. W. (1967). Paraplegia, 2, 262.

Merle D'Aubigne, R., Benassy, J. \& RAMAdier, T. O. (1956). Chirurgie Orthopedique des Paralysies, pp. 235 and 242. Paris: Masson.

PenNYBaCker, T. (1953). F. Bone foint Surg. I.

ROGERS, W. A. (I930). Surg. Gyn. Obstet. 50, IOI.

SCHMORL, G. (1927). Verh. dtsch. path. Ges. 22, 250.

TAYLOR, A. S. (1929). Am. Surg. 90, 32 I.

Verbiest, F. (1963). Symposium on Spinal Injuries, p. I I9. R. Coll. Surg. Edinburgh.

Watson-Jones, Sir Reg. (1931). F. Bone foint Surg. 13, 383.

Watson-Jones; Sir Reg. (1934). F. Bone foint Surg. 16, 30.

\section{Discussion: Afternoon Session}

\section{Chairman: Sir LUDwig GuTtManN}

Dr. Neubauer (Austria) showed pictures of a 26-year-old patient who at the age of I3 (I 957) developed a complete paraplegia below T8 following smallpox vaccination. Following rehabilitation, the patient was able to walk with the aid of calipers and crutches but in 1965 an ex-articulation of the left leg from the hip was performed because of a perforating decubitus. The left ischial ramus had been removed previously (I963). The patient was provided with a corset, which, however, produced a deep pressure sore below the right anterior iliac crest, which in 1968 was healed by plastic repair (fig I). As a result of the removal of the left leg, the patient developed a marked scoliosis (fig. 2). In order to counteract the scoliosis and, moveover, at the same time to relieve pressure from the buttocks, a special suspension corset, fixed on both sides of the side-arms of his wheelchair, was made, as shown in Figure 3, which enables the patient to sit upright and to continue his job as a telephone operator (fig. 4).

Dr. Meinecke (Germany). To Professor Adler: you demonstrated a case named Y. F. who made a very good recovery. I would be interested to know what was his initial neurological state at the beginning of his paraplegia. Perhaps I overlooked it on the slides.

Professor AdLER (Israel). This was a very odd case. He had a fracture of $\mathrm{C}_{5}$ and C6, but without dislocation and only slight compression with right monoparesis and right hyperalgesia. He recovered spontaneously with a certain kind of physiotherapy, but I am sure that without this physiotherapy he would have recovered too.

Dr. MeineCKe (Germany). To Dr. Katznelson: you demonstrated cases operated upon following traumatic lesions. How long did the follow-up study of these patients last? It would be very interesting to know what happened later on.

Dr. KATZNELSON (Israel). These patients treated by the Harrington method are recent cases. With the dual plates we have control of five years. One showed dis- 